\title{
Comprehensive study on ecological restoration and land exploitation of mining subsidence in suburbs of Chinese mining cities
}

\author{
Jinhua Zhou $\cdot$ Lejie Wang
}

Received: 20 July 2014/Revised: 8 August 2014/ Accepted: 10 August 2014/Published online: 1 October 2014

(C) The Author(s) 2014. This article is published with open access at Springerlink.com

\begin{abstract}
China has nearly a hundred mining cities derived from mining development. While mining development has brought about immense achievements in a city's economic construction, it has also resulted in different levels of damage to the eco-environment of the mining city, leaving behind a lot of subsided wasteland and heavily confining the sustainable development and transformation there. How to restore and exploit the land and eco-environment disrupted by mining development in an effective way, therefore, has become a pressing challenge that Chinese mining cities are facing. In this paper, the planning and construction of Nanhu Eco-city in the suburb of Tangshan City is analyzed as an example. After characterizing the coal-mining subsided lands in Kailuan Tangshan Mine originated in different periods and under different geological mining conditions and evaluating their safety level, the authors try to demonstrate how eco-restoration and comprehensive land exploitation should be implemented by making the best use of available local resources to achieve "economy-society-environment" sustainability and coexistence in a mining city.
\end{abstract}

Keywords Ecological restoration $\cdot$ Land exploitation $\cdot$ Mining subsidence $\cdot$ Mining city $\cdot$ Tangshan

\section{Introduction}

A mining city emerges or grows as a result of mineral resources development and in which mining plays the leading role or acts as a pillar industry within a period of time. It is the product when economic development moves into a certain historic stage (Song et al. 2013). Two features describe the characteristics of a mining city. One is the general feature of a city that plays a driving, radial and central role in the economy and society of a certain area. The other is mineral resources development as one of its main functions: mining makes great influence to the prosperity of the city and is inscribed in every aspect of the city (Li 1978; Hu 2001).

While mining development has brought about immense achievements in a city's economic construction, it has also

J. Zhou $\cdot$ L. Wang $(\bowtie)$

Tangshan Research Institute Co., Ltd., China Coal Technology

\& Engineering Group Corp, Tangshan 063012, China

e-mail: Wlj295@126.com resulted in different levels of damage to the eco-environment of the mining city, leaving behind a lot of subsided wasteland there. This is especially true for coal mining, which is already responsible for an aggregate of $110 \times$ $10^{4} \mathrm{hm}^{2}$ of subsided land and more than 50 billion yuan of economic damage. Calculated by population of the mine area, the per capita mined-out subsidence area is $1.864 \mathrm{hm}^{2}$ (Zhao 2006). At the coal-mining subsidence rate of $0.2-0.3 \mathrm{hm}^{2} /\left(10^{4} \mathrm{t}\right)$, China has approximately $(2.7-4.1) \times$ $10^{4} \mathrm{hm}^{2}$ of new subsided land every year. As the nation's coal industry continues to grow and coal output increases step by step, more coal-mining subsidence will appear, and the eco-environment in mine areas will deteriorate day by day. The sustainability of transformation of mining cities will be greatly confined. How to restore and exploit the land and eco-environment damaged by mining development in an effective way, therefore, has become a pressing challenge for Chinese mining cities. Combined with the example of the construction on coal-mining subsidences in Nanhu Eco-city in the suburb of Tangshan City, the authors give some insights into how to achieve the 
"economy-society-environment" sustainability and coexistence in a mining city.

\section{Origin of Tangshan Nanhu Eco-city}

Tangshan Nanhu Eco-city lies in the suburb of Tangshan City, covering an area of approximately 29 square kilometers. Located about $1 \mathrm{~km}$ from the downtown district of Tangshan City, the majority of this area falls within the coalfield boundaries of Kailuan Group Tangshan Mining Branch Company ("Kailuan Tangshan Mine" for short). In addition to some hundred million tonnes of coal resources, the century-long mining history in Kailuan Tangshan Mine ever since its establishment in 1878 has also resulted in massive coal-mining subsidence and numerous subsided water logging areas in the southern suburb of Tangshan City which, for many years, has been heavily laden with rubbish, weeds, effluent and mosquitoes (see Fig. 1). The yell for improving the city image and residents' living environment has forced the city to redefine its development orientation: they decided to include the development and construction of the former coal-mining subsidence area high on the list of considerations for the city's transformation into a resource-based city and name it Tangshan Nanhu Eco-city.

\section{Regional geological mining conditions}

Tangshan Nanhu Eco-city lies above the coalfield of Kailuan Group Tangshan Mining Branch Company ("Tangshan Mine" for short). See Fig. 2. Kailuan Tangshan Mine has a mining history of 136 years ever since its shaft No. 1 was drilled in 1878 . When the coal volume was verified in 1998, the coal mine production capacity was 3 million tonnes/year. Currently, the coal mine's annual production capacity is around 4 million tonnes/year. The Carboniferous Permian coal seams are typically exploited in the mine. Workable coal seams include coal seams 5, 8, 9, 12-1 and 12-2. Geological mining conditions in this mine can be summarized as follows: (1) Complex geological structure. Tangshan Mine lies at the southwestern end of the northwestern flank of Kaiping coalfield. The stratum strikes NE-SW. The structure is extremely complex with major faults FI, FII, FIII, FIV and FV arrayed in the north-to-south order. (2) Diverse coal seam occurrence types. Under the specific tectonism, steeply inclined coal seams, steeply reversed coal seams, inclined coal seams, gently inclined coal seams and horizontal coal seams are all distributed in the mine area. See Fig. 3. (3) Great mining time span, which is more than 80 years from 1926 to date. (4) Medium to thick coal seams, with cumulative
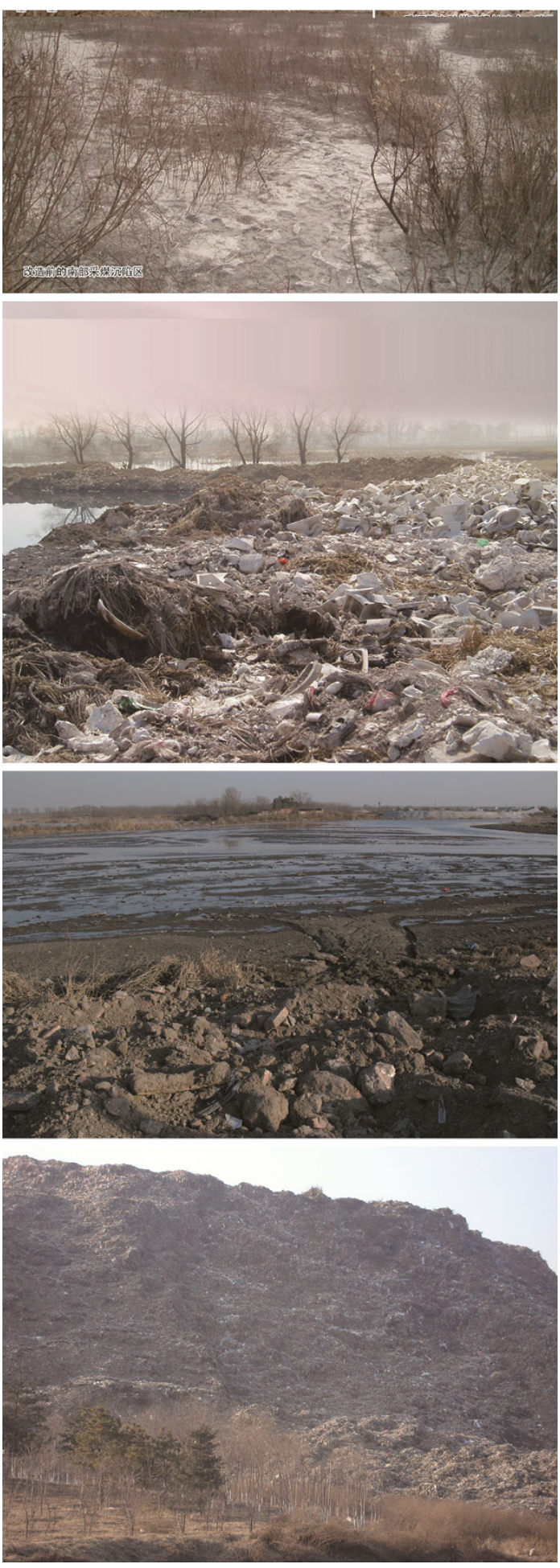

Fig. 1 Subsidences before comprehensive remediation

workable coal seam thickness of approximately $16 \mathrm{~m}$. (5) Diverse mining methods: drop stacking for steep coal seams, strike longwall mining face for horizontal and inclined coal seams, all cave-in method for roof control, inclined slicing for ultra thick coal seams, and metal mesh 
false roof or fully mechanized top coal caving method. (6) Nonuniform thickness distribution of the Quaternary stratum within the coalfield, which is thinner in the northeast and gradually thickens towards the southwest. The thickness ranges from 10 to $300 \mathrm{~m}$.

Besides, there are two local coal mines within the coalfield of Tangshan Mine: Liuzhuang and Zengsheng mines, which are focused on the steeply inclined coal seams and the reverse regions of coal seams in Tangshan Mine that were once exploited before Liberation.

\section{Stability and safety evaluation of coal mining subsidence}

The long mining time span, the large number of coal seams exploited, large cumulative thickness and great dip angle

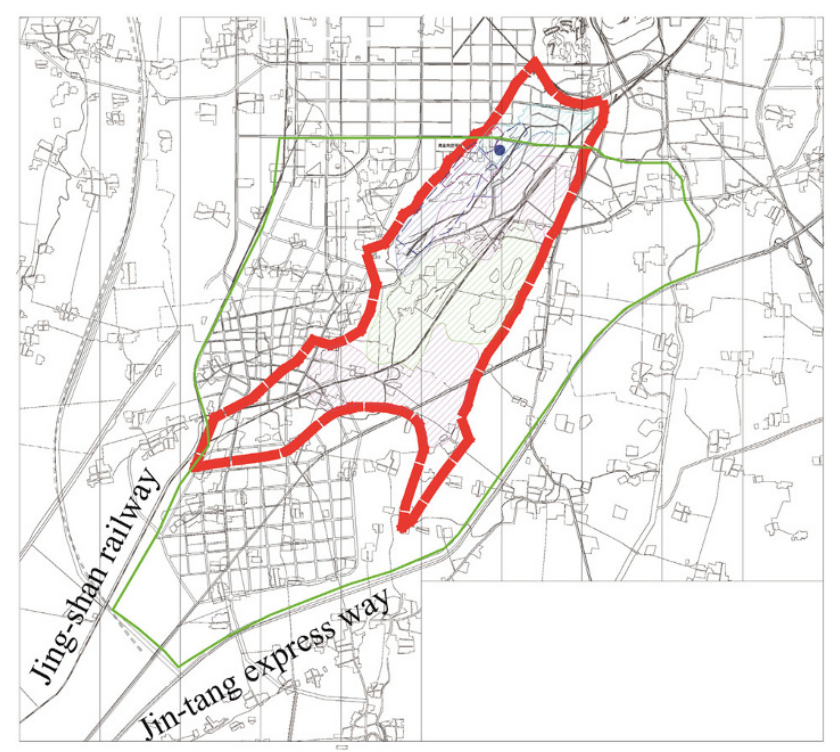

Fig. 2 Sketch showing the location of Nanhu Eco-city relative to Tangshan Mine variation have caused the different characteristics and safety levels of subsidences originated in different periods and under different geological conditions. In line with geological mining condition, subsidence lands originated from mining activities in the following periods are evaluated.

(1) Pre-1980: Mining was mostly carried out on or above level 9 in the old area of Tangshan Mine, with ground surface located to the north of Tangxu Road. Mining was targeted at coal seams 5, 8, 9 and 12. This region lies in a complex geological setting between faults I-III, to the north of fault I, which is a steeply inclined and reversed region. Mining was performed by drop stacking. The coal mining process was comparatively backward. Surface disruption typically occurs in the form of caving collapse at steeply inclined coal seam outcrops, concentrated surface deformation and fracture zones, and water logging pits resulted from surface subsidence. As no mining or excavation has been carried out on or above level 9 in the old area of Tangshan Mine over the past three decades, the mining-induced surface movement and deformation in this part has already stabilized. Except the steeply inclined coal seam outcrops and surface deformation and fracture zones, the safety of all the other regions is well secured.

(2) Post-1980: Mining was mostly carried out to the south of fault III, with ground surface located to the southeast of Tangxu Road, and to the north of West Wangjia. Mining was targeted at coal seams 5, 8, 9, 12-1 and 12-2. The maximum mining depth was around $900 \mathrm{~m}$. The coal seams are quite placid and the geological structure is comparatively simple. The alluvial deposits are quite thick. Mining methods used include high-grade conventional mining, fully-mechanized mining and fullymechanized top coal caving. Mining-induced surface disruption mainly occurs in the form of surface fractures and subsidence-related water logging. Calculated according to the duration of surface movement and deformation, mining activities in this region should have lasted for around

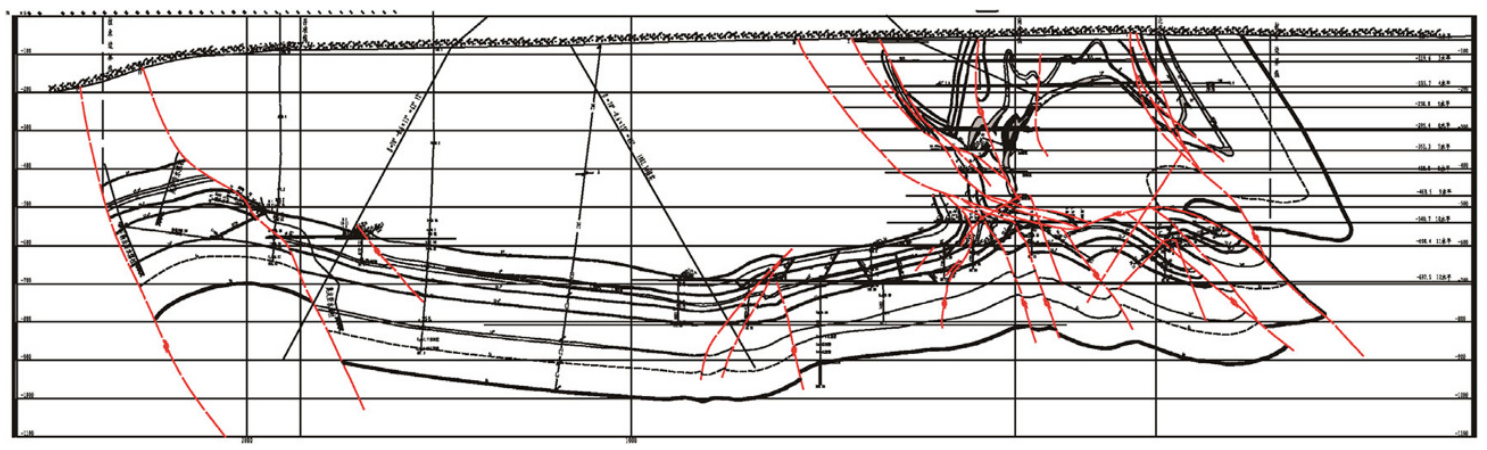

Fig. 3 Cross section showing the coal seam occurrence of Tangshan Mine 
6 years. Hence surface movement and deformation in regions exploited before 2008 have already stabilized with good safety while movement and deformation in regions exploited after 2008 are still in progress with a lower safety level.

(3) Current and future: Mining in Tangshan Mine is typically carried out to the east of East/West Wangjia, in the railway coal pillar region and the south flank region. Mining is targeted at coal seams 5,8 and 9. The cumulative mining thickness is around $14 \mathrm{~m}$. The maximum mining depth is around $1,000 \mathrm{~m}$. This region is subject to intense surface movement and deformation with a low safety level.

Comprehensive analysis of the mining time, mining methods and form of surface disruption has yielded Fig. 4: surface stability zonation plan of coal-mining subsidences in Nanhu Eco-city.

\section{Example of development planning and design of Nanhu Eco-city}

Based on the stability and safety evaluation results of the coal-mining subsidence lands in Nanhu Eco-city, in the light of the basic framework of the "General Urban Plan of Tangshan City (2003-2020)" and the social, economic, natural geographical conditions and current situation of the city, on the premise of respecting the current situation of the area, preserving the existing resources and inheriting the city's cultural heritage, the planning and design of Nanhu Eco-city made the best use of local resources at the site and was aimed at building a Nanhu eco-system that

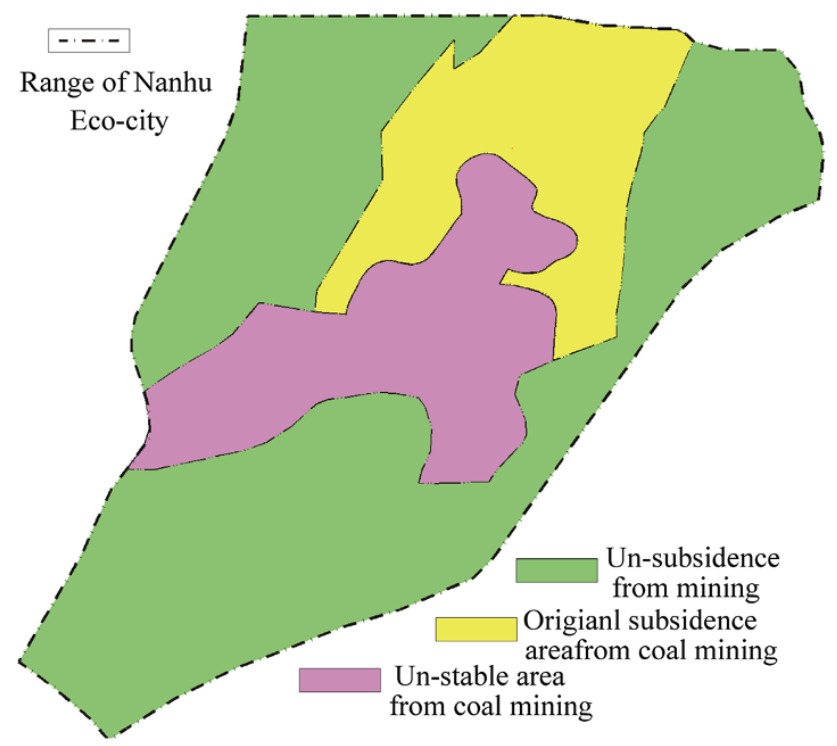

Fig. 4 Surface stability zonation plan of coal-mining subsidence lands in Nanhu Eco-city integrates eco-functions, landscape functions and recreational functions, gradually improving the urban eco-environment, structuring feature landscapes and meeting the development demand of the city. The design involved the least intervention in the site and incorporated landscape eco-restoration technology under the principle of respect for the local conditions, technical remediation and moderate exploitation. The Eco-city was designed to combine recreation, fitness, tourism, business with local history and culture, develop eco- and culture-based tourism projects, highlight industrial civilization and park landscaping, gradually improve the economic, eco- and social performances of Nanhu area, and eventually achieve the "economy-society-environment" sustainability and coexistence in the mining city. Figure 5 shows a bird's eye view and live shots of Tangshan Nanhu Eco-city.

\section{Technical measures}

As the core area of Tangshan Nanhu Eco-city is situated above the coal-mining subsidence area of Kailuan Tangshan Mine, landscaping and commercial development of this area should take anti-deformation technical measures for new buildings or structures to ensure their safe service. Technical measures include: (1) Intervene in the plane planning layout; (2) Limit the maximum height of buildings or structures to be built in or near a mined-out or mining-disturbed region; (3) Limit the unit length of buildings or structures according to the surface movement and deformation of the place where these buildings or structures are to be located; (4) Determine a foundation form that is rigid enough for mining-induced deformation; (5) Use a flexible sliding course for the foundation to absorb part of the surface movement and deformation; (6) Blend up surface movement and deformation using the building structure computational software PKPM, and take rigid measures for the foundation and superstructure to resist surface deformation.

\section{Conclusions}

Nanhu Eco-city, a miracle of scientific development and urban transformation, unrolls a picture of historic transmutation from industrial civilization toward eco-civilization. By scientific validation, logic planning and design, advanced technical measures and making the best use of local resources, Tangshan municipal government implemented mass eco-restoration and remediation to the southern coalmining subsidence lands in Tangshan Mine, turning a rubbish-laden, sparsely-populated, effluent-covered land into a 


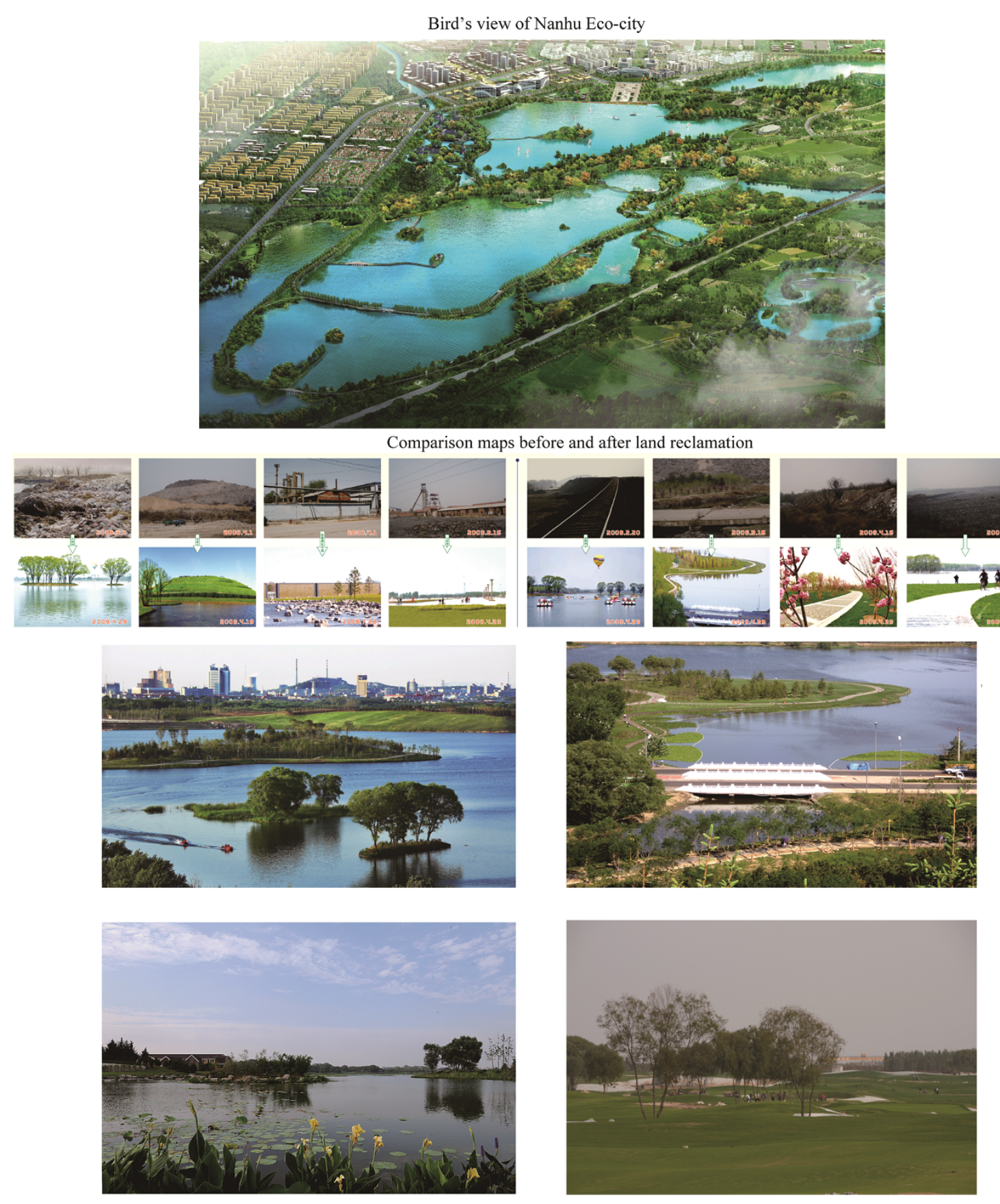

Fig. 5 Bird's eye view and live shots of Tangshan Nanhu Eco-city

luxuriantly green, man-water harmonious center Eco-park in the city, and eventually achieving "economy-societyenvironment" sustainability and coexistence in a mining city. The "Nanhu Eco-city" model will open up a new road to sustainability for Chinese mining cities.

Open Access This article is distributed under the terms of the Creative Commons Attribution License which permits any use, distribution, and reproduction in any medium, provided the original author(s) and the source are credited.

\section{References}

$\mathrm{Hu}$ K (2001) Basic problems of mining cities in China. Resour Ind 5:10

Li WY (1978) Industrial development and urban planning of Coal Mining City. Acta Geographica Sinica 45(3):63-77

Song J, Wang SJ, Ye Q, Wang XW (2013) Urban spatial morphology characteristic and its spatial differentiation of mining city in China. Areal Res Dev 31:1

Zhao JH (2006) Overview of studies on urban development of resource-based city in China. Urban Stud 13(3):86-91 